JEL Classification: M 31

ПРОЦЕСС ФОРМИРОВАНИЯ ИМИДЖА ПРЕДПРИЯТИЯ

Фёдорова В.А., к.э.н., доцент

Харьковский национальный автомобильно-дорожный университет;

Кирчатая И.Н., к.э.Н., доцент

Харьковский национальный автомобильно-дорожный университет

Постановка проблемы. Стремительный рост конкуренции на рынке товаров и услуг вынуждает предприятия задумываться о том, как они воспринимаются их целевыми группами. Сформировать в сознании целевых групп устойчивый образ предприятия, обеспечивающий видение в нем преимуществ, отсутствующих у конкурентов, позволяет наличие положительного имиджа. Таким образом, проблема формирования имиджа предприятия становится особо актуальной. Построение эффективного имиджа предприятия предполагает знание процесса его формирования. В связи с этим возникает задача обоснования содержания и последовательности работ при формировании имиджа предприятия.

Анализ последних исследований и публикаций. Анализ литературных источников [1-10] позволил сделать вывод, что в настоящее время среди исследователей нет единства мнений относительно количества и содержания этапов процесса формирования имиджа предприятия (табл. 1).

Таблица 1

Сравнительная характеристика этапов процесса формирования имиджа предприятия в различных исследованиях

\begin{tabular}{|c|c|c|}
\hline Автор & $\begin{array}{l}\text { Коли- } \\
\text { чество } \\
\text { этапов }\end{array}$ & Содержание этапов \\
\hline 1 & 2 & 3 \\
\hline $\begin{array}{c}\text { Шкардун В.Д., } \\
\text { Ахтямов Т.М. } \\
{[1, \text { с. } 70]}\end{array}$ & 6 & $\begin{array}{l}\text { 1) анализ маркетинговой среды предприятия и выделение целевых } \\
\text { групп общественности; } \\
\text { 2) формирование набора наиболее существенных имиджеобразующих } \\
\text { факторов для каждой из целевых групп общестенности; } \\
\text { 3) разработка желаемого образа предприятия (с точки зрения } \\
\text { установленных стратегических целей) для каждой целевой группы } \\
\text { общественности; } \\
\text { 4) оценка состояния имиджа предприятия в каждой из целевых групп } \\
\text { общественности; } \\
\text { 5) разработка и реализация плана мероприятий по формированию } \\
\text { позитивного имиджа предприятия в сознании целевых групп; } \\
\text { 6) контроль достигаемых результатов и коррекция (при необходимости) } \\
\text { плана }\end{array}$ \\
\hline $\begin{array}{c}\text { Блинов А.О., } \\
\text { Захаров В.Я. } \\
\text { [2, с. } 38]\end{array}$ & 5 & $\begin{array}{l}\text { 1) измерение имиджа: какой он? } \\
\text { 2) оценка имиджа: что должно быть сделано? } \\
\text { 3) разработка программы построения имиджа: как это будет сделано? } \\
\text { 4) осуществление программы; } \\
\text { 5) повторное измерение имиджа: какой он теперь? }\end{array}$ \\
\hline $\begin{array}{c}\text { Алешина И.В. } \\
\text { [3, с. 52]; } \\
\text { Ильяшенко С.М., } \\
\text { Колодка А.В. [4] }\end{array}$ & 3 & $\begin{array}{l}\text { 1) формулировка видения, корпоративной миссии; } \\
\text { 2) определение корпоративной индивидуальности, или «личности» } \\
\text { предприятия; } \\
\text { 3) формирование корпоративной идентичности (системы } \\
\text { коммуникативных средств, отражающих индивидуальность компании) }\end{array}$ \\
\hline
\end{tabular}


Продовження таблиці 1

\begin{tabular}{|c|c|c|}
\hline 1 & 2 & 3 \\
\hline Рид С. [5, с. 89] & 3 & $\begin{array}{l}\text { 1) формулировка фирменного стиля предприятия; } \\
\text { 2) оценка текущих действий; } \\
\text { 3) применение корпоративного имиджа к текущим вопросам }\end{array}$ \\
\hline $\begin{array}{l}\text { Федотова И.В., } \\
\text { Алюкаева В.Е. } \\
\quad[6, \text { с. } 68]\end{array}$ & 5 & $\begin{array}{l}\text { 1) оценка существующего имиджа предприятия; } \\
\text { 2) разработка концепции имиджа; } \\
\text { 3) формирование внешнего имиджа предприятия; } \\
\text { 4) формирование внутреннего имиджа предприятия; } \\
\text { 5) контроль выполнения имидж-программ предприятия }\end{array}$ \\
\hline Джи Б. [7] & 6 & $\begin{array}{l}\text { 1) определение цели формирования корпоративного имиджа; } \\
\text { 2) определение целевой аудитории, подробное ее изучение; } \\
\text { 3) разработка концепции корпоративного имиджа; } \\
\text { 4) оценка возможностей фирмы для формирования заявленного } \\
\text { корпоративного имиджа; } \\
\text { 5) формирование, внедрение и закрепление корпоративного имиджа в } \\
\text { сознании потребителя; } \\
\text { 6) оценка состояния корпоративного имиджа, контроль реализации } \\
\text { программы }\end{array}$ \\
\hline $\begin{array}{c}\text { Горчакова P.P. } \\
{[8, \text { с. 188] }}\end{array}$ & 4 & $\begin{array}{l}\text { 1) оценка первоначального имиджа; } \\
\text { 2) разработка плана по развитию (улучшению) имиджа; } \\
\text { 3) реализация разработанного плана; } \\
\text { 4) оценка сформированного имиджа }\end{array}$ \\
\hline $\begin{array}{l}\text { Семенчук Т.Б., } \\
\text { Басараб Н.А. } \\
\text { [9, с. } 475]\end{array}$ & 4 & $\begin{array}{l}\text { 1) оценка начального имиджа; } \\
\text { 2) разработка плана по развитию (улучшению имиджа); } \\
\text { 3) реализация созданного плана; } \\
\text { 4) оценка сформированного имиджа }\end{array}$ \\
\hline $\begin{array}{c}\text { Антонова Н.В. [10, с. } \\
475]\end{array}$ & 6 & $\begin{array}{l}\text { 1) формулировка имиджевых целей; } \\
\text { 2) анализ имиджевой аудитории; } \\
\text { 3) прорисовка имиджевых характеристик; } \\
\text { 4) соотнесение наличных и желаемых характеристик; } \\
\text { 5) выбор средств самопрезентации организации; } \\
\text { 6) воплощение имиджа в реальной жизни }\end{array}$ \\
\hline
\end{tabular}

Так, Шкардун В.Д. и Ахтямов Т.М. [1], Джи Б. [7], Антонова Н.В. [10, с. 475] предлагают начинать формирование имиджа предприятия с анализа его маркетинговой среды и выделения целевых групп. То есть первостепенным шагом, по их мнению, является определение предпочтений целевой аудитории и формирование на этой основе желаемого образа предприятия. В то же время такие исследователи как Рид С. [5], Алешина И.В. [3]; Ильяшенко С.М., Колодка А.В. [4] считают, что формирование имиджа следует начинать с конструирования желаемого образа предприятия, а уже потом разрабатывать мероприятия по его донесению до целевых групп.

Блинов А.О., Захаров В.Я. [2], Федотова И.В., Алюкаева В.Е. [6], Горчакова Р.Р. [8], Семенчук Т.Б., Басараб Н.А. [9, с. 475] в качестве начального этапа предлагают осуществлять оценку существующего имиджа предприятия, то есть исходят из того, что у предприятия имидж уже сформирован, если не целенаправленно, то стихийно. Исходя из результатов оценки, производится либо корректировка имиджа предприятия, либо поддержание его на достигнутом уровне.

Как показал анализ литературных источников, одна группа авторов [1, 3 $5,7]$ исходит из того, что имидж предприятия изначально не сформирован, и его нужно формировать или на основе собственных предпочтений, или на основе предпочтений целевых групп; а другая $[2,6,8,9]$ - что имидж уже 
сформирован, и его нужно или поддерживать на достигнутом уровне, или корректировать. В основе данного разделения лежит разное понимание способа формирования имиджа предприятия. Одни исследователи считают, что имидж полностью зависит от действий предприятия, и создается им целенаправленно, а другие - рассматривают возможность стихийного формирования имиджа под воздействием факторов, на которые предприятие полностью повлиять не может (при этом предприятию нужно определить свой имидж и при необходимости его скорректировать).

В работе [11] обосновано, что имидж формируется предприятием целенаправленно. То есть имидж является тем желаемым образом, который предприятие хочет предложить целевым группам, показывает, каким оно хочет себя видеть в глазах данных групп. Именно предприятие контролирует и решает, каким будет данный образ на основе анализа информации о предпочтениях целевых групп, а также установленных стратегических целей. Из этого следует вывод, что имидж формируется предприятием при выходе на рынок, то есть на стадии зарождения жизненного цикла. Либо же на стадии спада, когда имидж требует кардинальной перестройки. В дальнейшем задача предприятия сводится либо к улучшению, либо к поддержанию имиджа на достигнутом уровне за счет его корректировки в соответствии со стадией жизненного цикла (роста или зрелости).

Таким образом, исследователи, поддерживающие первый подход, описывают процесс формирования имиджа предприятия на стадии зарождения либо спада, а второй - на стадиях роста или зрелости.

В связи с этим предлагается при обосновании этапов процесса формирования имиджа предприятия исходить из того, на какой стадии жизненного цикла находится предприятие.

Нерешённые составляющие общей проблемы. Мнения исследователей расходятся относительно количества и содержания этапов процесса формирования имиджа предприятия. При этом при реализации процесса не учитывается стадия жизненного цикла предприятия.

Формулирование цели статьи. Усовершенствовать процесс формирования имиджа предприятия на основе учета в нем стадии жизненного цикла предприятия.

Изложение основного материала исследования. Для обоснования процесса формирования имиджа предприятия предлагается воспользоваться методологией структурного анализа IDEF0, которая предполагает построение контекстной и декомпозиционной диаграммы процесса.

Построение контекстной диаграммы позволяет дать общее описание исследуемого процесса как единого целого без его разделения на составные части. При этом процесс представляется в виде функционального блока со сторонами, имеющими следующие значения: левая - «вход», правая - «выход», верхняя - «управление», нижняя - «механизм». 
Процесс формирования имиджа предприятия реализуется на основе информации о стадии жизненного цикла предприятия, а также его миссии и цели (рис. 1).

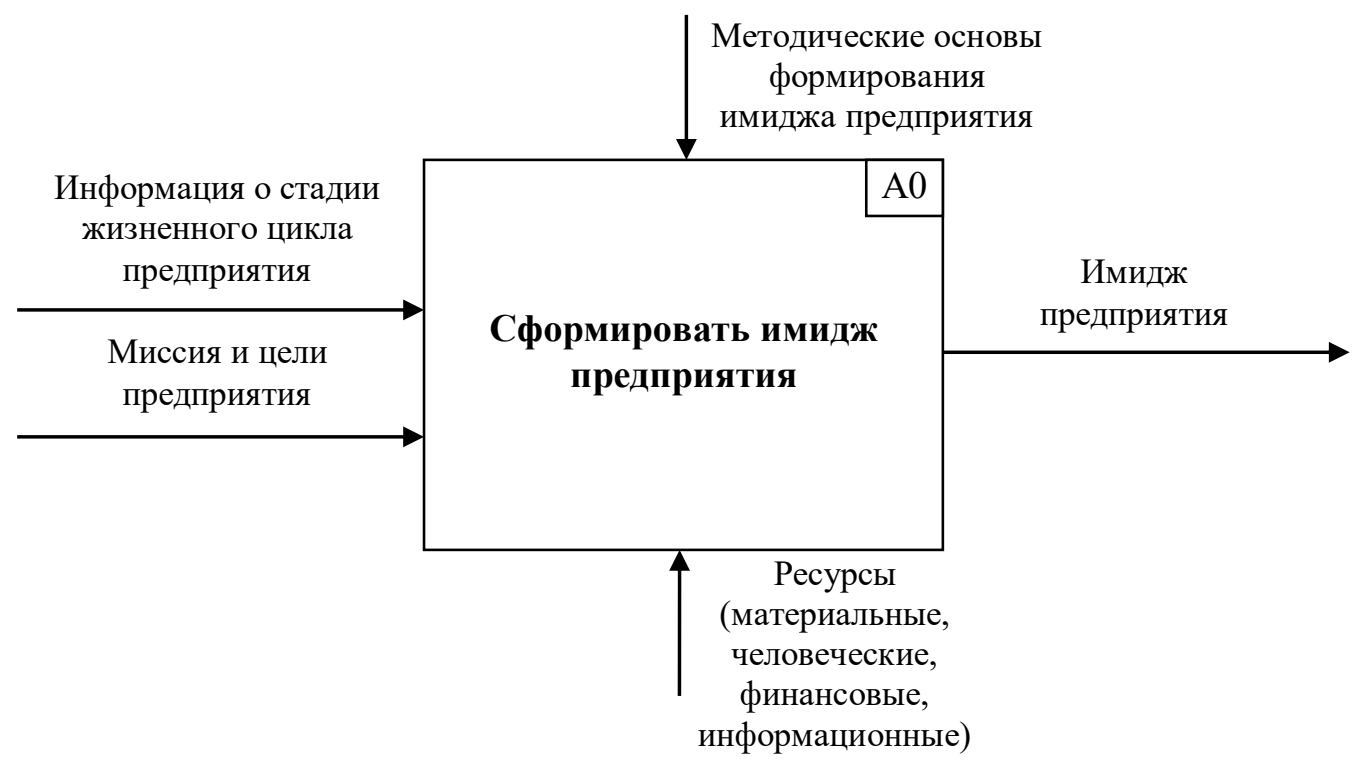

Рис. 1. Контекстная диаграмма процесса формирования имиджа предприятия

В качестве «механизма» выступают все имеющиеся у предприятия виды ресурсов (материальные, человеческие, финансовые, информационные). При реализации процесса предприятие руководствуется методическими основами формирования имиджа предприятия. «Выходом» процесса является достигнутый уровень имиджа предприятия.

Отобразить внутреннее строение исследуемого процесса позволяет построение его декомпозиционной диаграммы (рис. 2-3). Если предприятие находится на стадии зарождения (выходит на рынок) или же на стадии спада жизненного цикла (когда имидж требует кардинальной перестройки), то первым этапом процесса формирования имиджа предприятия является определение целей формирования имиджа (рис. 2).

Далее осуществляется анализ маркетинговой среды предприятия и выделение целевых групп. Под целевыми группами понимаются субъекты, непосредственно взаимодействующие с предприятием либо оказывающие на него определенное влияние (работники предприятия, клиенты, контактные аудитории и т.д.), для которых собственно и разрабатывается имидж. Изучение особенностей целевой аудитории позволяет предприятию разработать концепцию имиджа предприятия. Поскольку ресурсы любого предприятия являются ограниченными, необходимо оценить наличие возможностей для формирования заявленного имиджа.

Если же предприятие уже некоторый период существует на рынке и находится на стадии роста или зрелости, то на первом этапе осуществляется оценка его имиджа (рис. 3). На основе полученной информации об уровне имиджа предприятия, a также текущей стадии жизненного цикла разрабатывается план мероприятий по улучшению (на стадии роста) или поддержанию (на стадии зрелости) имиджа в сознании целевых групп. 


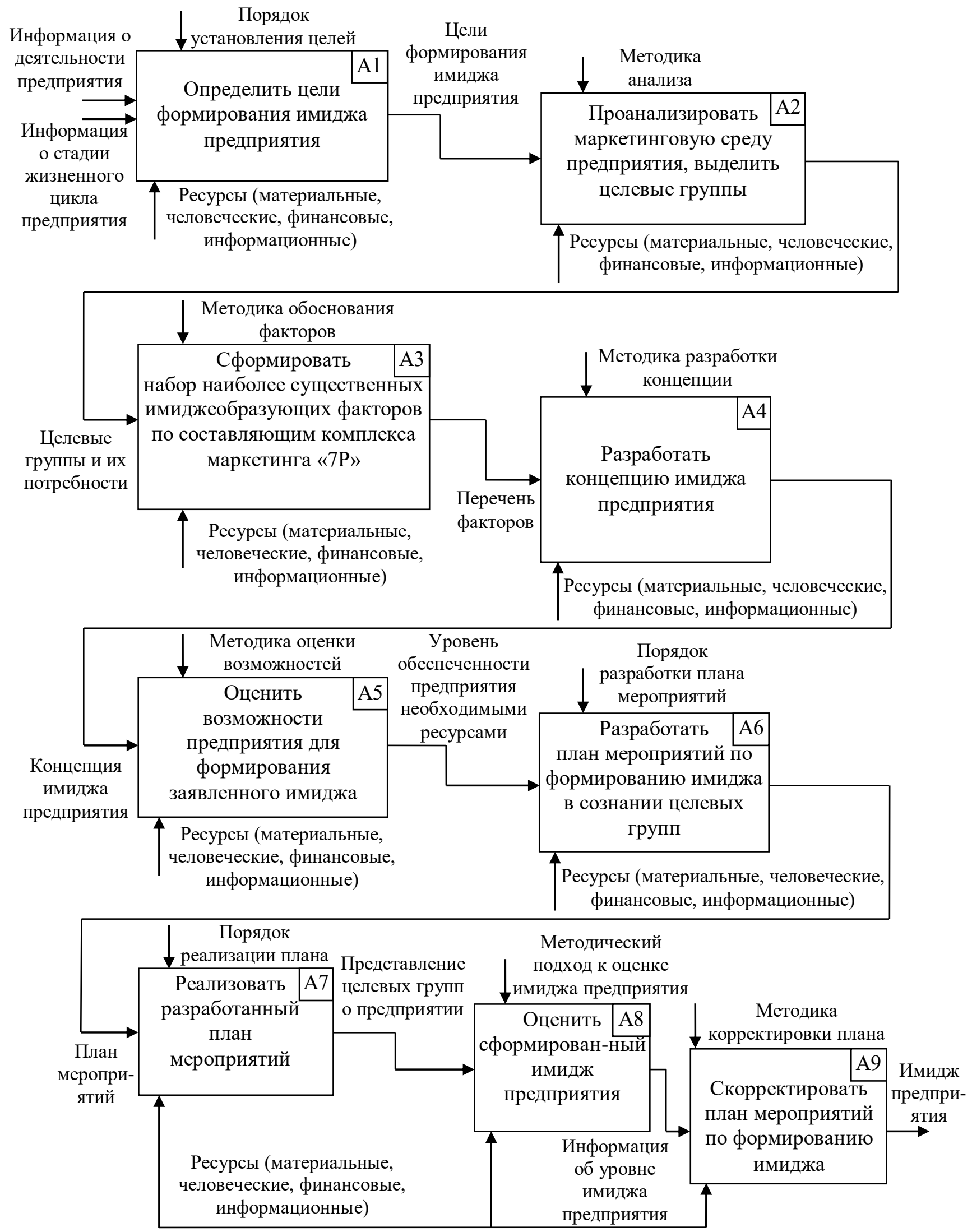

Рис. 2. Декомпозиционная диаграмма процесса формирования имиджа предприятия первого уровня (на стадии зарождения и спада жизненного цикла) 


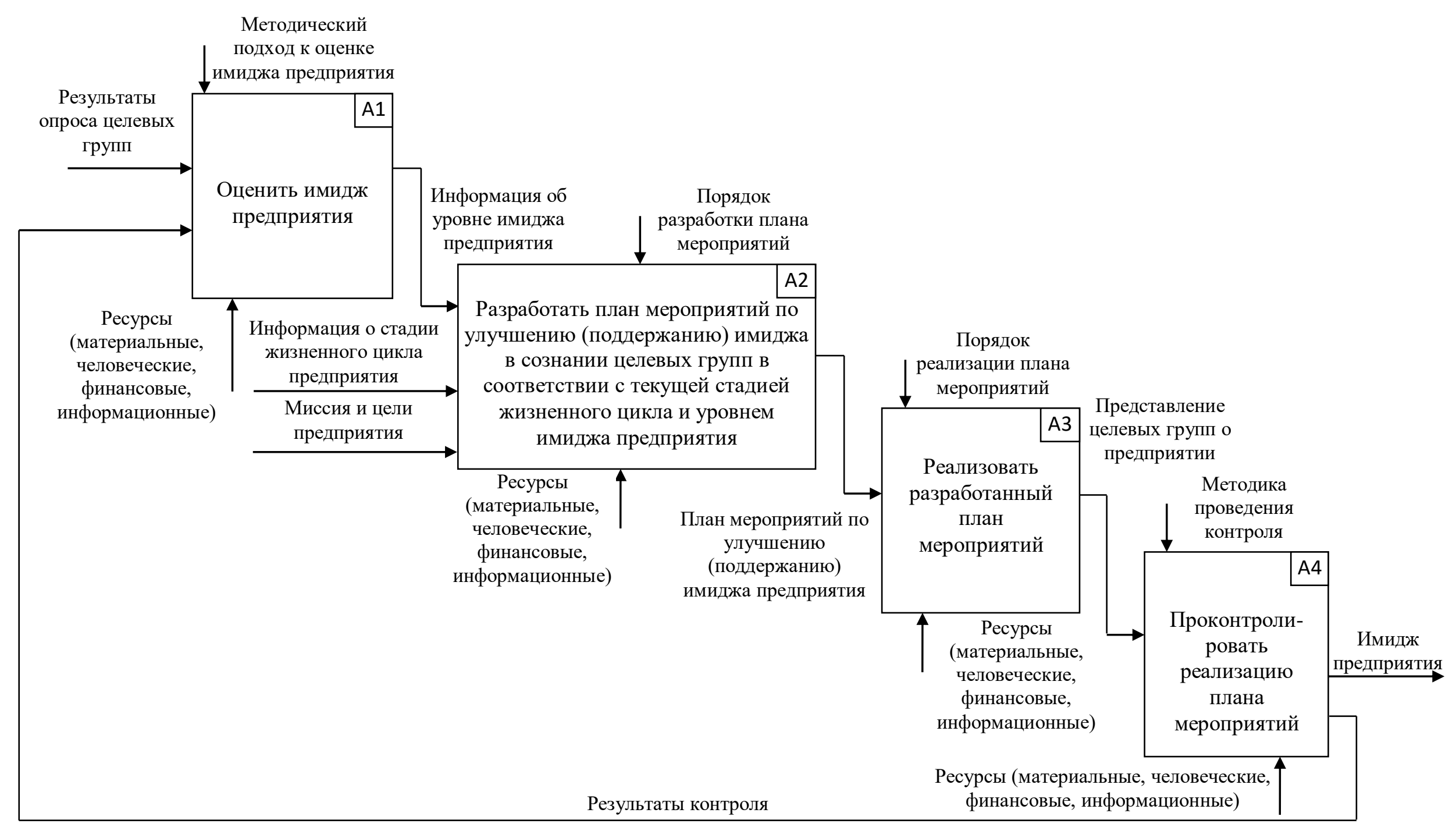

Рис. 3. Декомпозиционная диаграмма процесса формирования имиджа предприятия первого уровня (на стадии роста и зрелости жизненного цикла) 
Далее осуществляется разработка плана мероприятий по формированию имиджа в сознании целевых групп. Целевая аудитория воспринимает сконструированный имидж предприятия с помощью четырех сенсорных каналов: визуального, слухового, обонятельного и осязательного. В связи с этим осуществляется перевод требуемых характеристик предприятия в вербальную, визуальную, событийную и контекстную формы. Воздействие на сенсорные каналы осуществляется с помощью инструментов комплекса маркетинга [12]. Для предприятий сферы услуг комплекс маркетинга включает семь элементов: физическое окружение, контакты с персоналом, цена, услуга, распределение, коммуникации, процесс). С целью определения того, насколько сконструированный имидж предприятия соответствует ожиданиям целевых групп, осуществляется его оценка. По ее результатам предприятие осуществляет контроль достигнутых результатов и при необходимости корректировку имиджа.

Данный план разрабатывается, исходя из текущего уровня имиджа, а также стадии жизненного цикла предприятия. То есть осуществляется формирование услуги, выбор ценовой политики, формируется физическое окружение, налаживается процесс предоставления и распределения услуг, обеспечивается продвижение услуг. Далее осуществляется реализация разработанного плана, а также контроль его реализации.

Выводы из проведенного исследования. Таким образом, усовершенствован процесс формирования имиджа предприятия, разработанный с использованием методологии функционального моделирования IDEF0. В отличие от существующих, данный процесс предполагает учет стадии жизненного цикла предприятия.

\section{Перечень ссылок}

1. Шкардун В. Д., Ахтямов Т. М. Оценка и формирование корпоративного имиджа предприятия. Маркетинг в России и за рубежсом. 2001. № 3. С. 68-77.

2. Блинов А. О., Захаров В. Я. Имидж организации как фактор ее конкурентоспособности. Менеджмент в России и за рубежом. 2003. № 4. С. $35-44$.

3. Алешина И. Корпоративный имидж. Маркетинг. 1998. № 1. С. 50-54.

4. Ілляшенко С. М., Колодка А. В. Імідж організації як економічна категорія: сутність, зміст, основні етапи формування. Прометей. 2012. №2(38). C. $164-170$.

5. Рид С. Эффективно ли вы поддерживаете свой корпоративный имидж? Маркетинг. 2008. №6. С. 86-90.

6. Федотова И. В., Алюкаева В. Е. Процесс формирования имиджа автотранспортного предприятия. Економіка транспортного комплексу: зб. наук. праць. Вип. 17. Х. : ХНАДУ, 2011. С. 62-74.

7. Джи Б. Имидж фирмы: планирование, формирование, продвижение. М. : «Центр», 1999. 273 с. 
8. Горчакова Р.Р. Особенности формирования корпоративного имиджа. Известия высших учебных заведений. Поволжский регион. 2012. № 2 (22). С. 185-192.

9. Семенчук Т. Б., Басараб Н. А. Формування іміджу підприємства. Економіка і суспільство. Випуск № 7. 2016. С. 473-477.

10. Антонова Н. В. Психология массовых коммуникаций: учебник и практикум для академического бакалавриата. М.: Издательство Юрайт, 2019. $373 \mathrm{c.}$

11. Федорова В. О. Формування іміджу автотранспортного підприємства: монографія. Харків: ХНАДУ, 2017. 120 с.

12. Шинкаренко В. Г. Особенности комплекса маркетинга в предприятиях транспорта. Вісник економіки і промисловості. 2012. № 38. С. 361-365.

\section{References}

1. Shkardun, V. D., Akhtyamov, T. M. (2001), Assessment and formation of the enterprise corporate image [Ocenka i formirovanie korporativnogo imidzha predprijatija], Marketing in Russia and abroad, No 3, P. 68-77.

2. Blinov, A. O., Zakharov, V. Ya. (2003), The organization image as a factor in its competitiveness [Imidzh organizacii kak faktor ee konkurentosposobnosti], Management in Russia and abroad, No. 4, P. 35-44.

3. Aleshina, I. (1998), Corporate image [Korporativnyj imidzh], Marketing, No 1, P. 50-54.

4. Ilyashenko, S.M., Kolodka, A.V. (2012), The organization image as an economic category: essence, content, main stages of formation [Imidzh orhanizatsii yak ekonomichna katehoriia: sutnist, zmist, osnovni etapy formuvannia], Prometheus, No 2 (38), P. 164-170.

5. Reed, S. (2008), Do you effectively maintain your corporate image [Jeffektivno li vy podderzhivaete svoj korporativnyj imidzh], Marketing, No 6, P. 8690 .

6. Fedotova, I. V., Alyukaeva, V. E. (2011), The process of motor transport enterprise image building [Process formirovanija imidzha avtotransportnogo predprijatija], Economy of a transport complex, Issue No 17, Kh.: KHNADU, P. 6274.

7. Gee, B. (1999), The company image: planning, formation, promotion [Imidzh firmy: planirovanie, formirovanie, prodvizhenie], M.: "Center", 273 p.

8. Gorchakova, R.R. (2012), Features of the corporate image formation [Osobennosti formirovanija korporativnogo imidzha], News of higher educational institutions, Volga region, No 2 (22), P. 185-192.

9. Semenchuk, T.B., Basarab, N.A. (2016), Formation of enterprise image [Formuvannia imidzhu pidpryiemstva], Economy and society, Issue No 7, P. 473-477.

10. Antonova, N. V. (2019), The Psychology of Mass Communications [Psihologija massovyh kommunikacij], A Textbook and Workshop for Academic Baccalaureate, M.: Publishing house Yurayt, 337 p. 
11. Fedorova, V. A. (2017), Formation of motor transport enterprise image [Formuvannia imidzhu avtotransportnoho pidpryiemstva], monograph, Kharkov: KhNADU, $120 \mathrm{p}$.

12. Shynkarenko, V. G. (2012), Features of the marketing mix in transport enterprises [Osobennosti kompleksa marketinga v predprijatijah transporta], News of Economy and Promotionality, No 38, P. 361-365.

\section{PЕФЕРАТИ РЕФЕРАТЫ ABSTRACTS \\ УДК 339.138; JEL Classification: М 31 ПІДПРИЕМСТВА \\ Федорова В.О., Кирчата І.М. ПРОЦЕС ФОРМУВАННЯ ІМІДЖУ}

Mema: удосконалити процес формування іміджу підприємства на основі врахування в ньому стадії життєвого циклу підприємства. Методика дослідження: методологія функціонального моделювання IDEF0 - для графічного представлення складу та структури процесу формування іміджу підприємства в залежності від стадії його життєвого циклу. Результати дослідження: в статті обгрунтовано, що зміст та послідовність етапів процесу формування іміджу підприємства зумовлюється стадією його життєвого циклу. Доведено, що, імідж формується підприємством «з нуля» у двох випадках: 1) на стадії зародження при виході підприємства на ринок; 2) на стадії занепаду, коли імідж вимагає кардинальної перебудови. При переході на наступні стадії завдання підприємства зводиться або до поліпшення іміджу (на стадії зростання), або до його підтримки на досягнутому рівні (на стадії зрілості). При цьому створення, поліпшення або підтримання іміджу повинно здійснюватися за рахунок використання заходів, виділених за елементами комплексу маркетингу, які відповідають поточній стадії життєвого циклу та рівню іміджу підприємства. Таким чином, запропоновано процес формування іміджу підприємства, кількість і зміст етапів якого визначається стадією життєвого циклу підприємства. Моделювання процесу здійснено на підставі графічної нотації IDEF0. Наукова новизна: удосконалено процес формування іміджу підприємства, представлений $з$ використанням методології функціонального моделювання IDEF0, який, на відміну від існуючих, передбачає врахування стадії життєвого циклу підприємства. Практична значущість: знання послідовності і змісту етапів процесу формування іміджу дозволить підприємству сконструювати бажаний образ, який гарантує тривале функціонування та успіх на ринку.

Ключові слова: імідж підприємства; процес формування; методологія IDEF0; стадія життєвого циклу підприємства; створення; поліпшення; підтримання; елементи комплексу маркетингу.

УДК 339.138; JEL Classification: М 31

\section{Федорова В.А., Кирчатая И.Н. ПРОЦЕСС ФОРМИРОВАНИЯ ИМИДЖА ПРЕДПРИЯТИЯ}

Цель: усовершенствовать процесс формирования имиджа предприятия на 
основе учета в нем стадии жизненного цикла предприятия. Методика исследования: методология функционального моделирования IDEF0 - для графического представления состава и структуры процесса формирования имиджа предприятия в зависимости от стадии его жизненного цикла. Результаты исследования: в статье обосновано, что содержание и последовательность этапов процесса формирования имиджа предприятия обусловлены стадией его жизненного цикла. Доказано, что имидж формируется предприятием «с нуля» в двух случаях: 1) на стадии зарождения при выходе предприятия на рынок; 2) на стадии спада, когда имидж требует кардинальной перестройки. При переходе на последующие стадии жизненного цикла задача предприятия сводится либо к улучшению имиджа (на стадии роста), либо к его поддержанию на достигнутом уровне (на стадии зрелости). Создание, улучшение или поддержание имиджа должно осуществляться за счет использования мероприятий, выделенных по элементам комплекса маркетинга, которые соответствуют текущей стадии жизненного цикла и уровню имиджа предприятия. Таким образом, предложен процесс формирования имиджа предприятия, количество и содержание этапов которого определяется стадией жизненного цикла предприятия. Моделирование процесса осуществлено на основе графической нотации IDEF0. Научная новизна: усовершенствован процесс формирования имиджа предприятия, представленный с использованием методологии функционального моделирования IDEF0, который, в отличие от существующих, предполагает учет стадии жизненного цикла предприятия. Практическая значимость: Знание последовательности и содержания этапов процесса формирования имиджа позволит предприятию сконструировать желаемый образ, гарантирующий длительное функционирование и успех на рынке.

Ключевые слова: имидж предприятия; процесс формирования; методология IDEF0; стадия жизненного цикла предприятия; создание; улучшение; поддержание; элементы комплекса маркетинга.

\section{UDC 339.138; JEL Classification: M 31}

\section{Fedorova V.A., Kirchataya I.N. THE PROCESS OF ENTERPRISE IMAGE FORMING}

Purpose: to improve the process of the enterprise image forming on the basis of taking into account the stage of enterprise life cycle. Methodology of research: IDEF0 functional modeling method - for a graphical representation of the composition and structure of the image formation process of the enterprise, depending on the stage of its life cycle. Findings: the article substantiates that the content and sequence of stages of the process of the enterprise image forming are determined by the stage of its life cycle. It is proved that the image is formed by the enterprise "from scratch" in two cases: 1) at the stage of launch when the enterprise enters the market; 2) at the stage of decline, when the image requires a fundamental restructuring. In the transition to the subsequent stages of the life cycle, the task of the enterprise is either to improve the image (at the growth stage), or to maintain it at 
the achieved level (at the maturity stage). Creation, improvement or maintenance of the image should be carried out through the use of activities identified by the elements of the marketing mix, which correspond to the current stage of the life cycle and the level of the enterprise image. Thus, the process of the enterprise image forming is proposed, the number and content of the stages of which are determined by the stage of the enterprise life cycle. Modeling of the process is based on graphical notation IDEF0. Originality: the process of the enterprise image forming has been improved. It has been presented using the function modeling method IDEF0. It is different from the existing ones as it takes into account enterprise's life cycle stages. Practical value: knowledge of the sequence and content of the stages of the image formation process will allow the enterprise to construct the desired image, which guarantees long-term functioning and success in the market.

Key words: enterprise image; formation process; IDEF0 method; stage of the enterprise life cycle; creation; improvement; maintenance; elements of the marketing mix.

\section{Відомості про авторів / Сведения об авторах / About the Authors}

Федорова Вікторія Олександрівна - кандидат економічних наук, доцент, Харківський національний автомобільно-дорожній університет, доцент кафедри економіки i підприємництва, м. Харків, Україна; e-mail: pobedaviktory5@gmail.com; ORCID ID: https://orcid.org/0000-0003-2318-2153. Моб. (066) 345-66-81

Федорова Виктория Александровна - кандидат экономических наук, доцент, Харьковский национальный автомобильно-дорожный университет, доцент кафедры экономики и предпринимательства, г. Харьков, Украина

Fedorova Viktoriya - Candidate of Sciences (Economics), Associate Professor, Kharkov National Automobile and Highway University, Associate Professor of the Department of Economics and Entrepreneurship, Kharkov, Ukraine

Кирчата Ірина Миколаївна - кандидат економічних наук, доцент, Харківський національний автомобільно-дорожній університет, доцент кафедри економіки i підприємництва, м. Харків, Україна; e-mail: kirchatayairina@gmail.com; ORCID ID: https://orcid.org/0000-0002-0270-1586. Моб. (050) 669-00-96

Кирчатая Ирина Николаевна - кандидат экономических наук, доцент, Харьковский национальный автомобильно-дорожный университет, доцент кафедры экономики и предпринимательства, г. Харьков, Украина

Kirchataya Irina Nikolaevna - Candidate of Science (Economics), Associate Professor, Kharkov National Automobile and Highway University, Associate Professor of the Department of Economics and Entrepreneurship, Kharkov, Ukraine 